\title{
Sustained improvement in left ventricular function after successful coronary angioplasty
}

\author{
R A Perry, A Singh, A Seth, E Jane Flint, A Hunt, R G Murray, M F Shiu
}

\begin{abstract}
The short and long term effects of successful percutaneous transluminal coronary angioplasty on left ventricular function at rest and on exercise were investigated in 49 patients. Thirty four had had no previous infarction (group 1) and 15 had (group 2). Technetium-99m gated blood pool images were obtained at rest and during exercise before, six weeks after, and a mean of fifteen months after successful angioplasty. Before angioplasty the mean (SD) ejection fraction fell significantly on exercise in both groups from $58(10) \%$ to $53(13) \%$ in group 1 and from $48(10) \%$ to $40(16) \%$ in group 2 . This change was paralleled by a worsening wall motion score (from 0.6 $(0.4)$ to $1.6(1.2)$ in group 1 and from 2.3 $(1.9)$ to $3.3(2.4)$ in group 2). Six weeks after the procedure there was little change in resting ejection fraction but it increased significantly on exercise (to 62 (11)\% in group 1 and to $53(13) \%$ in group 2). There was a concomitant significant improvement in the exercise wall motion score (to $0.4(0.6)$ in group 1 and to $1.8(1.1)$ in group 2). This improvement in exercise ejection fraction and wall motion was maintained at later follow up with no significant deterioration in either variable and a clearly sustained improvement in ejection fraction (60 $(10) \%$ in group 1 and 51 (10)\% in group 2) and wall motion score $(0.2(0 \cdot 2)$ in group 1 and $1.3(0.8)$ in group 2$)$ compared with values before angioplasty.

The initial improvement in left ventricular function on exercise after successful angioplasty was maintained for at least 9-24 months both in patients with previous myocardial infarction and in those without.
\end{abstract}

Coronary angioplasty is now a well established treatment for atheromatous coronary artery disease and has been shown to be efficacious in a wide variety of clinical circumstances. ${ }^{1-3}$ A technically successful procedure was usually associated with an immediate improvement in patients' symptoms, exercise tolerance, and myocardial perfusion. ${ }^{45}$ There was also evidence of a short term improvement in left ventricular function on exercise though there was little change in resting function. ${ }^{6-8}$

Long term clinical and angiographic follow up of percutaneous transluminal coronary angioplasty is now well documented. There was a $30^{\circ}$ incidence of early restenosis, but a successful procedure was associated with lasting relief of angina for up to eight years with a small percentage of patients developing new disease in other segments of the coronary circulation. ${ }^{9}$ There are few studies of long term changes in left ventricular function after successful angioplasty. Kent and coworkers followed up 19 patients for six months after successful primary angioplasty and showed sustained improvement in left ventricular function on exercise over this period. ${ }^{6}$ The long term benefits of angioplasty in patients who have poor resting left ventricular function have not been specifically examined.

We obtained gated blood pool images from 58 patients at rest and during exercise before and six weeks after a successful angioplasty procedure. Those who remained symptom free (49) were reinvestigated by the same technique 9-24 months (mean 15 months) after the procedure to assess the long term changes in left ventricular ejection fraction and wall motion. The patients were analysed as two groups, according to whether or not they had sustained a previous myocardial infarction. We did this to study the benefits in patients with poor initial resting left ventricular function.

\section{Patients and methods}

PATIENTS

A total of 58 patients underwent gated blood pool studies at rest and on exercise before and six weeks after a successful coronary angioplasty procedure. In seven of these patients restenosis of the target vessel developed during the follow up: five had repeat angioplasty and two underwent coronary artery bypass grafting. New disease developed in one patient who then underwent grafting and one patient moved from the region and was lost to follow up. Thus of the original 58 patients there were 49 with no evidence of any cardiac event or clinical/angiographic evidence of restenosis who were followed up. All of them initially presented with chronic stable angina refractory to medical treatment. The mean age of the group was 54 years and the ratio of males to females was 5:1. Thirty four patients had no previous history of myocardial infarction and fifteen had had previous $Q$ wave infarction. Because the presence of previous infarction is likely to influence resting and 
Age, sex, and target vessel in both groups of patients

\begin{tabular}{|c|c|c|}
\hline & $\begin{array}{l}\text { No previous MI } \\
\text { (group 1) }\end{array}$ & $\begin{array}{l}\text { Previous MI } \\
\text { (group 2) }\end{array}$ \\
\hline $\begin{array}{l}\text { Number } \\
M: F\end{array}$ & $\begin{array}{l}34 \\
6: 1\end{array}$ & $\begin{array}{l}15 \\
4: 1\end{array}$ \\
\hline Age (mean) (yr) & 52 & 56 \\
\hline Target vessel: & & \\
\hline $\begin{array}{l}\text { LAD } \\
\text { RCA }\end{array}$ & $19 \quad\left(56^{\circ} \mathrm{o}\right)$ & $(73 \%)$ \\
\hline $\mathrm{RCA}$ & $\left(35^{\circ}\right)$ & $(14 \%)$ \\
\hline $\mathrm{Cx}$ & $(9 \%)$ & $(13 \%)$ \\
\hline Multivessel PTCA & 5 & 0 \\
\hline
\end{tabular}

$\mathrm{Cx}$, circumflex coronary artery; $\mathrm{LAD}$, left anterior descending coronary artery; RCA, right coronary artery; PTCA, percutaneous transluminal coronary angioplasty.

exercise left ventricular function groups 1 and 2 will be considered separately.

The table shows the patients' characteristics and target vessels. The two groups of patients share similar baseline characteristics. More patients in group 2 had disease of the left anterior descending coronary artery but this difference was not statistically significant. All the patients in group 2 underwent angioplasty to the infarct related vessel. Five patients in group 2 had a second vessel dilated. The mean percentage stenosis of the normal vessel diameter was $87 \%$ in group 1 and $82 \%$ in group 2. This was reduced to a mean value of $15 \%$ in both groups after successful dilatation

Follow up gated blood pool studies were carried out a mean of 15 months after the angioplasty procedure (range 9-24 months) as described below.

GATED BLOOD POOL STUDIES

Three sets of radionuclide images were obtained at rest and on exercise in each patient. Antianginal medication, apart from sublingual nitrate, was stopped 48 hours before each investigation and patients attended in a preabsorbtive state. Red cells were labelled in vivo with $740 \mathrm{mBq}$ of technetium$99 \mathrm{~m}$ pertechnetate 20 minutes after the administration of stannous chloride. Images were acquired with a Picker mobile gamma camera with a high sensitivity collimator electrocardiographically gated at 24 frames per cardiac cycle. Images at rest were obtained over 2 minutes with patients supine and the camera in the $30^{\circ}$ left anterior oblique position with $5^{\circ}-10^{\circ}$ of caudal tilt to obtain maximal chamber separation with clear septal separation of the right and left ventricles. The camera angles were noted and were repeated for any individual patient in subsequent studies.

Graded exercise images were obtained with the patient in the same position on a bicycle ergometer, starting at $25 \mathrm{~W}$ and increasing by $25 \mathrm{~W}$ until the onset of angina or to a maximum of $100 \mathrm{~W}$. Each exercise level was maintained for three minutes to allow one minute to reach equilibrium and a 2 minute image acquisition period. At six week and long term follow up all but five of the patients were able to exercise to a higher level than at the initial investigation ( 40 to one $25 \mathrm{~W}$ increment and four to two $25 \mathrm{~W}$ increments).

Data were analysed on a DEC 11 computer, and the global ejection fraction was calculated at rest and maximum exercise by a semiautomated edge detection algorithm that compensated for a moving region of interest. A wall motion image was generated and displayed on a closed loop cine. The left ventricle was divided into three regions of interest: free wall, apex, and septum. Each segment was graded from 0 to 4 where $0=$ normal wall motion and $4=$ frank dyskinesia. Images were examined by two experienced observers. Linear regression analysis of the interobserver scores gave correlation coefficients of 0.94 and 0.85 for ejection fraction and wall motion analysis respectively.

CORONARY ANGIOPLASTY

Angioplasty was carried out by one of two principal operators via the transfemoral route in all patients. A steerable balloon system was used and patients were treated with aspirin (300 $\mathrm{mg}$ once a day), nifedipine (10 $\mathrm{mg}$ three times a day), isosorbide dinitrate ( $10 \mathrm{mg}$ three times a day), intravenous nitrates, and heparin during the procedure. A successful procedure was defined as a reduction of the percentage stenosis to $<50 \%$ of the diameter of the nearest normal vessel segment with no major complication such as myocardial infarction, emergency or elective coronary artery bypass grafting, or death.

\section{STATISTICAL ANALYSIS}

Values for the groups are expressed as mean (SD). Data at rest and on exercise before and after angioplasty were compared by Student's paired $t$ test. Differences in baseline patient characteristics were evaluated by $\chi^{2}$ testing. All statistical analysis was performed with the Minitab statistics package (Minitab, State College, Pennsylvania 16801).

\section{Results}

Figures 1 and 2 show the short and long term changes in left ventricular function.

GROUP 1

Before angioplasty the mean resting ejection fraction in patients without previous myocardial infarction was $58(10) \%$ and this fell on exercise to a mean of $53(13)(p<0.05)$. Six weeks after successful angioplasty the resting ejection fraction was unchanged $(58(8) \%$ ) but there was a significant rise in the exercise ejection fraction to $62(11) \%$. These changes were paralleled by the changes in mean wall motion score $-0.6(0.4)$ and $1.6(1.2)$ at rest and on exercise before angioplasty and $0.3(0.4)$ and $0.4(0.6)$ after angioplasty.

At long term follow up the mean resting ejection fraction was $53(8) \%$ and the improvement in mean exercise ejection fraction over values before angioplasty was maintained $(60(10) \%(p<0.002)$. At long term follow up the mean resting wall motion score was $0 \cdot 2(0.3)$ and on exercise it was $0.2(0.2)$.

GROUP 2

The mean resting ejection fraction in patients with previous infarction (48 (10)\% was lower 
Figure 1 Changes in mean ( $S D$ ) ejection fraction before and after successful angioplasty and at long term follow up.
Figure 2 Changes in mean (SD) wall motion score before and after successful angioplasty and at long term follow up.

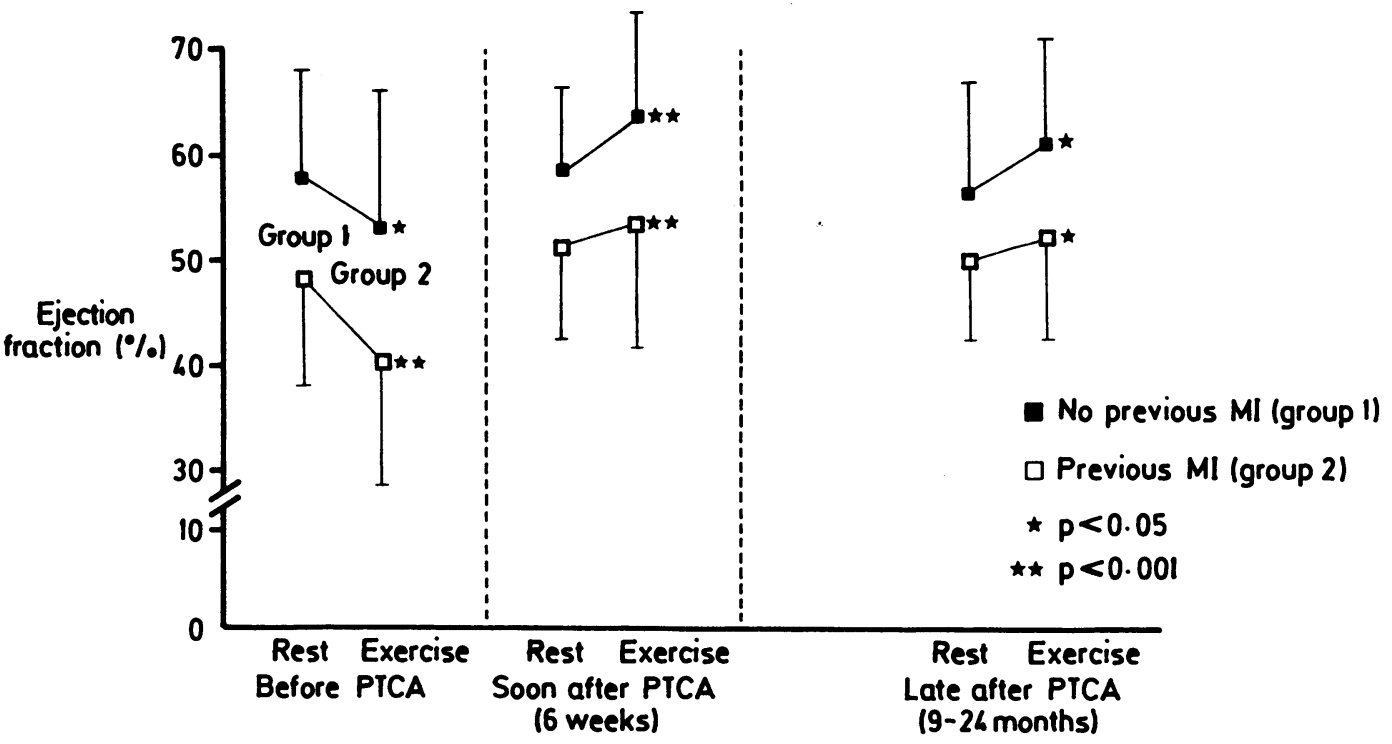

than group 1 patients and fell significantly to 40 (16)\% $(\mathrm{p}<0.001)$ on exercise. The resting ejection fraction rose to $52(9) \%$ after successful angioplasty but this change was not statistically significant. The mean exercise ejection fraction after angioplasty was $53 \%$ (13), which was significantly higher than the value before angioplasty $(\mathrm{p}<0.001)$. The mean wall motion score before angioplasty was $2.3(1.9)$ at rest and $3.3(2.4)$ on exercise. The exercise score was significantly improved after angioplasty $(1.8(1.1)(p<0.005))$. There was a fall in resting wall motion score that did not achieve statistical significance $(1 \cdot 8(1 \cdot 6))$.

At long term follow up the mean resting ejection fraction in these patients was $49(7 \%)$ and the mean exercise ejection fraction was 51 $(10) \%$. Mean wall motion score at rest was 0.9 $(0.9)$ and $1.2(0.9)$ on exercise.

\section{Discussion}

Though there have been various studies of the effect of percutaneous transluminal coronary angioplasty on left ventricular function in the short term ${ }^{7-9}$ there are few data on long term follow up. In addition, these studies did not specifically examine different subsets of patients with differing degrees of impairment of left ventricular function.

Our study confirms the findings of others that successful angioplasty improves left ventricular function during exercise at early follow up but has little effect on values at rest. As expected, patients with previous myocardial infarction had lower resting ejection fractions, higher wall motion scores, and their change on exercise before angioplasty was more striking than in patients with angina only.

In group 2 there was a modest improvement in resting ejection fraction and wall motion score after angioplasty. There were, however, wide individual variations so as a group these changes were not statistically significant. It may be that in the patients who did show an improvement a component of their resting dysfunction was the result of "hibernating" myocardium at rest caused by a compromised coronary circulation with reduced metabolic activity of some still viable myocardium. ${ }^{1011}$

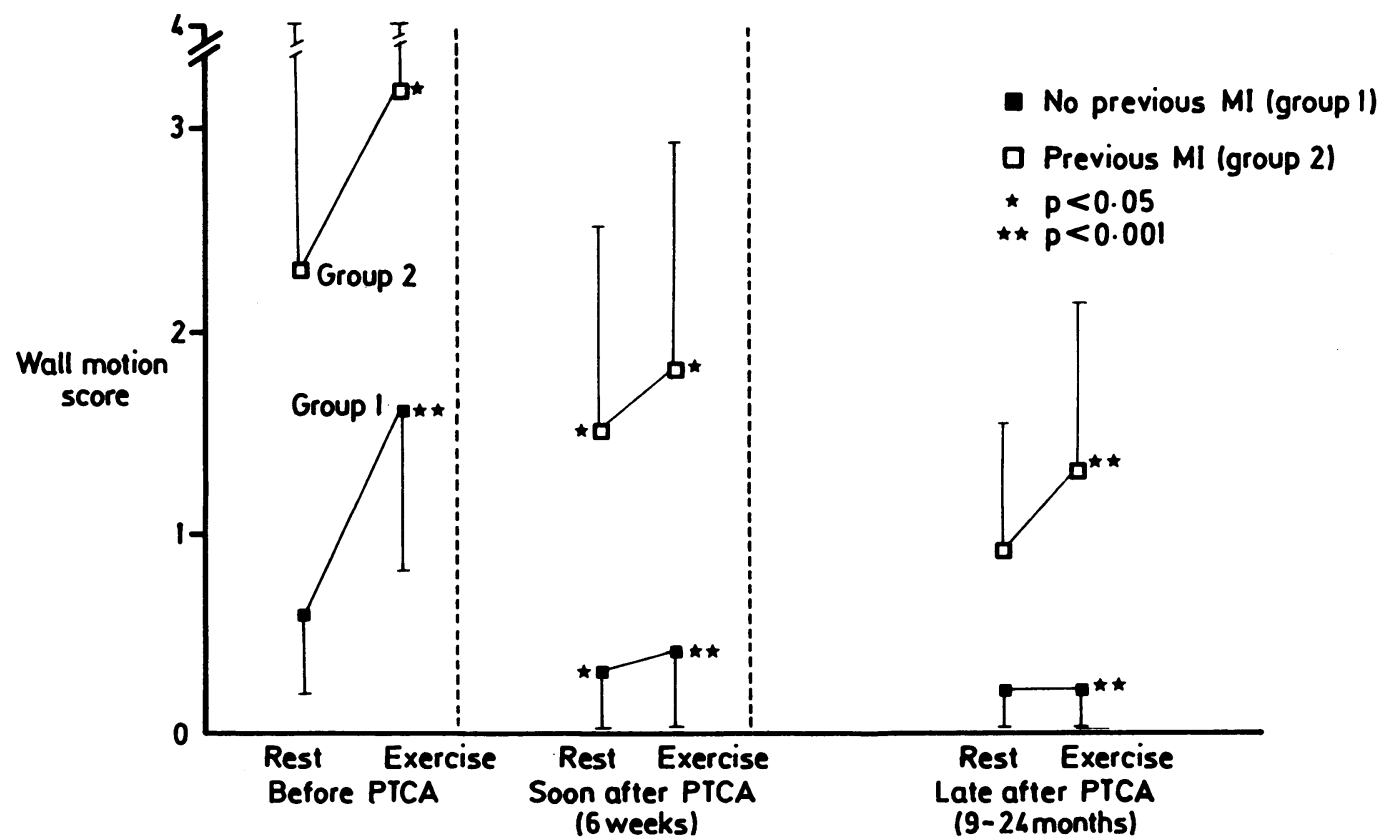


We have previously reported a case of substantial improvement in left ventricular function at rest and on exercise in a patient after successful dilatation of a severe subtotal left anterior descending stenosis. ${ }^{12}$ The peak exercise ejection fraction and wall motion score after angioplasty were significantly improved in group 2 patients but the exercise response was still abnormal. In patients with no previous myocardial infarction (group 1) resting function did not improve but after a successful procedure the response to exercise was normal.

The principal findings of this study are that the short term improvement in left ventricular ejection fraction and wall motion score in both groups of patients was maintained at least 9-24 months later. Clearly these are selected patients who have no symptoms suggesting restenosis. Without routine repeat angiographic studies it is possible that some of the study patients had a degree of restenosis in the absence of symptoms. It has been shown that $4 \%$ of symptom free patients have angiographic evidence of restenosis. ${ }^{13}$ This may account for the slightly lower mean resting ejection fraction in the group without infarction. Five patients, two in group 1 and three in group 2, showed a significantly abnormal exercise response at long term follow up but they had also shown an abnormal response at six week follow up. All five had repeat angiography on the basis of the technetium scan despite the absence of symptoms but none showed angiographic evidence of restenosis. Radionuclide ventriculography at rest and on exercise was used to identify patients with restenosis but the predictive value of the test in all patients, with and without symptoms, was $73 \%{ }^{14}$

In the patients with previous myocardial infarction the tendency towards an improved wall motion score continued beyond six weeks. This may be due to long term improved perfusion of previously hibernating myocardium but the results from this study are not conclusive. Evaluation of the changes in wall motion in a single projection should be viewed with caution; the change was small and did not reach statistical significance. It is encouraging that these patients with compromised left ventricular function did not deteriorate in the long term.
After successful coronary angioplasty the improvement in left ventricular ejection fraction and wall motion score, as assessed by radionuclide studies at rest and on exercise, was maintained at a mean long term follow up period of 15 months. This was true both of patients with previous infarction and of those without. In patients with infarction resting function was abnormal. Long term clinical success at angioplasty was paralleled by long term functional improvement in these indices of left ventricular function.

R A P was supported by a British Heart Foundation junior research fellowship. We thank Ms R Kambo for helping to prepare this paper.

1 DeFeyter PJ, Serruys PW, Arnold A, et al. Coronary angioplasty of the unstable angina related vessel in patients with multivessel disease. Eur Heart $J$ 1986;7: 460-7.

2 Cowley MJ, Vetrovec GW, DiSciascio G, et al. Coronary angioplasty of multiple vessels: short term outcome and long term results. Circulation 1985;72:1314-20.

3 Melchiro JP, Meier B, Urban P, et al. Percutaneous transluminal coronary angioplasty for total coronary arterial occlusion Am J Cardiol 1987;59:535-8.

4 Hirzal HO, Nuesch K, Siale RG, et al. Short and long term changes in myocardial perfusion after percutaneous transluminal coronary angioplasty assessed by thalliumtransluminal coronary angioplasty assessed by thallium-

5 Scholl JM, Chaitman BR, David PR, et al. Exercise electrocardiography and myocardial scintigraphy in the serial evaluation of the results of percutaneous transluminal coronary angioplasty. Circulation 1982;66:380-90.

6 Kent KM, Bonow DR, Ewals EJ, et al. Improved myocardial function during exercise after successful percutaneous transluminal coronary angioplasty. $N$ Engl J Med 1982; 306:441-6.

7 Sigwart U, Gerbic M, Essinger A, et al. Improvement in left ventricular function following percutaneous transluminal coronary angioplasty. Am J Cardiol 1982;49:651-7.

8 Rosing DR, Van Raden MJ, Mincemoyer RM, et al. Exercise, electrocardiographic and functional responses after percutaneous transluminal coronary angioplasty. $\mathrm{Am}$ J Cardiol 1984;53:36C-41C.

9 Greuntzig AR, King SB, Schlumpf M. Long term follow up after percutaneous transluminal coronary angioplasty. $N$ after percutaneous transluminal

10 Rahimtoola SH. A perspective on three large multicentre randomised trials of coronary artery bypass surgery for chronic stable angina. Circulation 1985;72 (suppl 5): 123-35.

11 Braunwald E, Rutherford JD. Reversible ischaemic left ventricular dysfunction; evidence for the hibernating myocardium. J Am Coll Cardiol 1986;8:1467-70.

12 Singh A, Perry RA, Shiu MF. Myocardial salvage following elective angioplasty for total coronary occlusion. Cathe Cardiovasc Diagn 1989;17:132-4.

13 Cowley MT, Mullin SM, Kelsey MF, et al. Early and long term results of percutaneous transluminal coronary angioplasty: National Heart, Lung and Blood Institute PTCA plasty: National Heart, Lung and

14 DePuey EG, Leatherman LL, Leachman RD, et al. Restenosis after transluminal coronary angioplasty detected with exercise-gated radionuclide ventriculography. J Am with exercise-gated radionuclid 